\title{
Early Growth Stages of the Rare Acridocarpus orientalis in the UAE-A First Step towards Conservation
}

\author{
Taoufik Ksiksi ${ }^{1}$, Chedia Guenaoui ${ }^{2}$, Nael Fawzi ${ }^{1,3}$ \\ ${ }^{1}$ Biology Department, Faculty of Science, United Arab Emirates University, Al Ain, UAE; ${ }^{2}$ Arid Regions Institute, Medenine, Tuni- \\ sia; ${ }^{3}$ Flora \& Phyto-Taxonomy Research Department, Agricultural Research Center, Giza, Egypt. \\ Email: tksiksi@uaeu.ac.ae
}

Received January $11^{\text {th }}, 2012$; revised February $14^{\text {th }}, 2012$; accepted February $25^{\text {th }}, 2012$

\begin{abstract}
The seed germination and seedling establishment of the rare Acridocarpus orientalis were investigated to understand its requirements for further seedlings establishment in the United Arab Emirates (UAE). It is an important first step in order to try to conserve the species and prevent its disappearance. The experiments were carried out in a greenhouse and in a laboratory under a temperature of about $25^{\circ} \mathrm{C} \pm 4^{\circ} \mathrm{C}$. Seeds were soaked in water or kept in cold conditions. A control treatment was also included. Only a total of 9 seeds emerged during a period that exceeded eight months. Percent germination in the laboratory experiment reached a maximum of 32\%, 75 days into the trial. The rate of seed mortality was $64 \%$. It may be a problem of acclimation to the greenhouse environment. The results of this study showed that $A$. orientalis seeds were not dormant. About $32 \%$ of seeds germinated and all others were viable. Soaking seeds in water proved to be the best treatment for $A$. orientalis to emerge. Further investigations of the species germination and establishment are needed in order to improve our chances of protecting $A$. orientalis in the wild.
\end{abstract}

Keywords: Qafas; Seed Germination; Seed Mortality

\section{Introduction}

The United Arab Emirates (UAE), like the other Golf states, is facing severe environmental challenges mainly because of economic development and urbanization, which resulted in higher pressures on demands for the natural resources. Climatic conditions coupled with anthropogenic activities are causing much of the pressure on the natural ecosystems. The anthropogenic factors are the prime cause of degradation [1]. The UAE is characterized by a bi-seasonal Mediterranean climate with high temperatures and low rainfall. Like in any desert dominated regions, soils are poor in organic matter, with relatively low biological activities. Such harsh conditions result in extreme losses of vegetation cover and floral biodiversity [2]. Much of these ecosystems are becoming increasingly degraded from Dubai to Abu Dhabi [3]. In arid and semiarid climate zones, desertification, land degradation and declining precipitation rates increasingly limit crop cultivation [4]. Additionally, widespread soil salinity restricts the potential of recovery in many parts of the UAE desert ecosystems. For instance, Haloxylon salicornicum, only slightly tolerant of salt, is replaced by Zygophyllum qatarense as soil salinity is increasing [5]. Numerous recent studies indicated that the natural heritage of Abu Dhabi is threatened by urbanization, infrastructure development, population growth and overgrazing. Habitat loss and degradation and species loss are expected to be detrimental outcomes. Overgrazing, for instance, had a serious effect on the natural vegetation, especially palatable plant species as a result of increased grazing pressures [6]. A decline in floral diversity is a direct, and sometimes irreversible, outcome of such increased pressure. Overgrazing has already led to the disappearance of Rhanterium epapposum and Panicum turgidum in many parts of the UAE [5]. In addition to $R$. epapposum, some palatable perennial grasses have substantially declined due to overgrazing [7]. Some shrubs may replace other more palatable ones as a result of heavy grazing. Some studies reported that other species are replacing R. epapposum in central Saudi Arabia [8], northern Africa [9] and Kuwait [10]; due to overgrazing. For instance, Zygophyllum mandavillei was thought to be widespread in the interior of the UAE, is actually restricted to a small area of Southern Arabia [11].

Long-term management decisions are to be adopted to reverse the downward trend in species, cover and biodiversity loss in the UAE deserts. Much of the benefits of biodiversity could be restricted. Acridocarpus orientalis is one species that has many ecological as well as medicinal advantages. It is rare and prone to extinction. The current field work led by the authors show that only 
less than 200 individuals are present in the wild. It is only restricted to a small area within Jebel Hafit [12]. But its current status in the UAE is unknown. Information on its growth habits will be a good start for proper management. Combined laboratory and field approaches are believed to be an adequate strategy to try to understand the growth habits of $A$. orientalis. Transplanting greenhouse grown plants could be an effective method to introduce A. umbellata, a rare and threatened species indigenous to the Pacific Coast of North America [13]. This will assist successes of reintroduction for conservation purposes, especially for species with few remaining wild populations [13]. Descriptions of effective procedures for these plant propagation and establishment in the field are decisive to progress the practice of species re-establishment [14]. The efficiency of this alternative was also justified by [15].

The present project attempts at understanding some of the germination requirements of $A$. orientalis. The study of seed germination is the first step in such conservation approach [16]. Specifically here in the UAE, where there is a lack of knowledge about the vegetation [3]. Improved understanding of the germination requirements of any plant species, and in particular the rare and endemic species, is of crucial importance for its conservation and management. The primary objective of this work is to understand the germination characteristics of $A$. orienttalis and ultimately create a nursery of that could be used to rehabilitate ecosystems where it was once growing within the UAE. In this part we focused on the germination from seeds as a step to produce seedlings.

\section{Material and Methods}

\subsection{Study Site}

United Arab Emirates (UAE) is surrounded by the Persian Gulf to the north, Sultanate of Oman and Saudi Arabia to the south, the Gulf of Oman and Sultanate of Oman to the east, and Qatar and Saudi Arabia to the west. The UAE is located between latitudes 22 degrees and 26.5 degrees north, and longitudes 51 degrees and 56.5 degrees east. Abu Dhabi is the largest Emirate in the UAE, with an area of $67,340 \mathrm{~km}^{2}$, which constitute about $87 \%$ of the UAE total area. The remaining few wild A. orientalis individuals are concentrated in a small wadi (a dry river) within Jabal Hafeet mountain (E55 $46^{\prime}$ and N $\left.24^{\circ} 05^{\prime}\right)$, the highest peak in Abu Dhabi Emirate.

\subsection{Variables Measured}

Seeds of A. orientalis were collected between September 2009 and February 2010. Two different experiments were carried out. The first was conducted in the UAE University greenhouse (October 2009), in which temperature was controlled by cooling chillers, and the second was conducted in the ecology laboratory (February 2010). For the greenhouse trial, seeds were divided into three groups. The first group was sown directly without submitting any treatment (Control), the second group was soaked in water and the third group was treated by cold temperature before their germination. The aim was to assess the best preplantation treatment on emergence. Seeds were then planted directly in 5-liter pots and placed in the greenhouse, where the ambient temperature was $25^{\circ} \mathrm{C}\left( \pm 4^{\circ} \mathrm{C}\right)$ and under the natural day/night cycle.

For the laboratory trial, seeds of A. orientalis were soaked in water during 48 hours at ambient temperature $\left(25^{\circ} \mathrm{C}\right.$ to $\left.28^{\circ} \mathrm{C}\right)$. After soaking, ten seeds per replicate were placed within an incubator (Binder ${ }^{\circledR}$ ) in $9 \mathrm{~cm}$ diameter Petri dishes, with a cotton layer that was regularly moistened to saturation with distilled water. The aim was to prevent dehydration during germination. The incubator was pre-set to a constant temperature of $23^{\circ} \mathrm{C}$ with a cycle of 10 hours light and 14 hours dark. For this second assay, 250 seeds were used with 25 replicates. Seeds were considered as germinated when the radical reached more than $1 \mathrm{~mm}$ in length [17]. Recording of germinated seeds was stopped when there was no further germination for one week. The number of germinated seeds was recorded daily and the Mean Time to Germinate (MTG) and the \% germination were determined. Photos were taken for germinated seeds in all germination stages.

\section{Results}

The results of the greenhouse trial demonstrated that the different seed treatments did not result in high sprouting rates. Only a total of 9 seeds emerged during a period that exceeded eight months. The first plants emergence was recorded in 25/11/2009 where 2 seedlings emerged from the water treated seeds and 1 plant emerged from the cold treated ones. Four more plants emerged later in 9/12/2009 then 2 more plants emerged in 16/12/2009, all from the water treated seeds. No plants emerged from the non treated seeds. In 15//03/2010 one plant from the water treated died. In 25/03/2010 two other plants (also water treated seeds) were dead. There were no significant differences between plants issued from water and cold treated seeds (Figure 1) that reached the same growth stage and all of them reached 8 leaves in May 2010.

The laboratory experiment showed a relatively higher percent germination of $32 \%, 75$ days into the trial (Figure 2). However, the rate of seed mortality was 64\%. The majority of the mortality cases occurred right after seeds germination. Seeds germinated after 2 to 7 days and the MTG in this assay was 27 days.

The beginning of the radical emergence occurred one week into the trial. Close observations of the seed germination processes revealed that this species has long and well developed roots. As it is shown in Figure 3, 

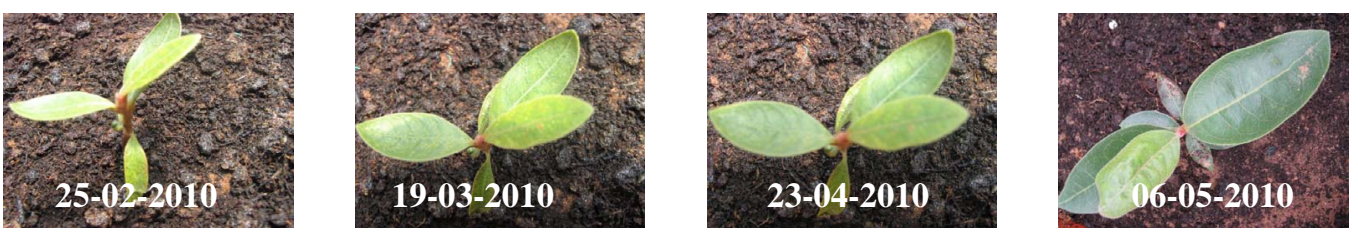

(a)
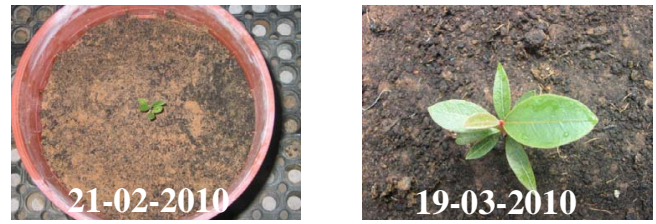

(b)

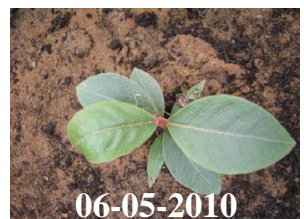

06-05-2010

Figure 1. Acridocarpus orientalis growth stages in the greenhouse as a result of cold treated seeds (a) and water treated seeds (b).

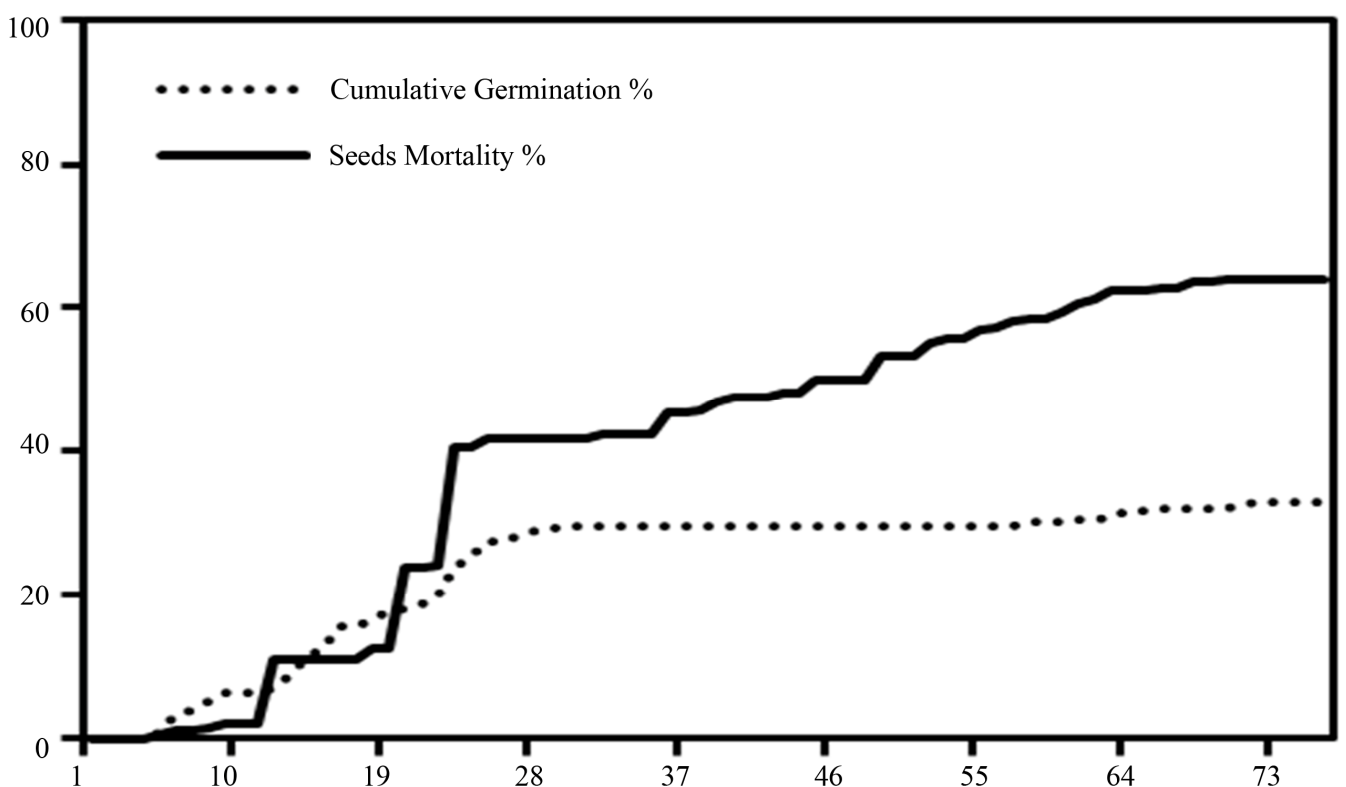

Figure 2. Cumulative germination and mortality rates of Acridocarpus orientalis seeds.
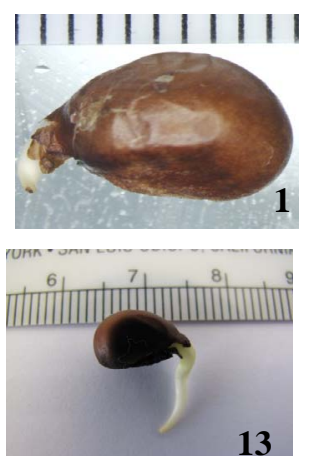

13
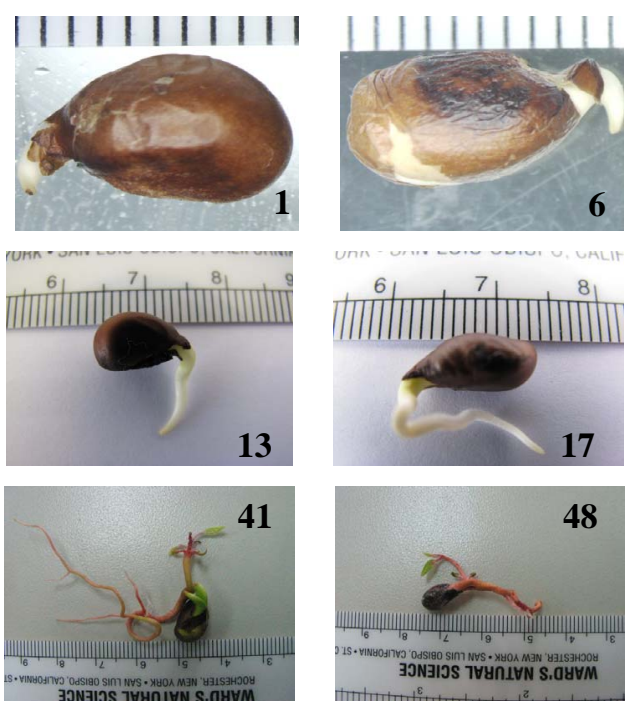
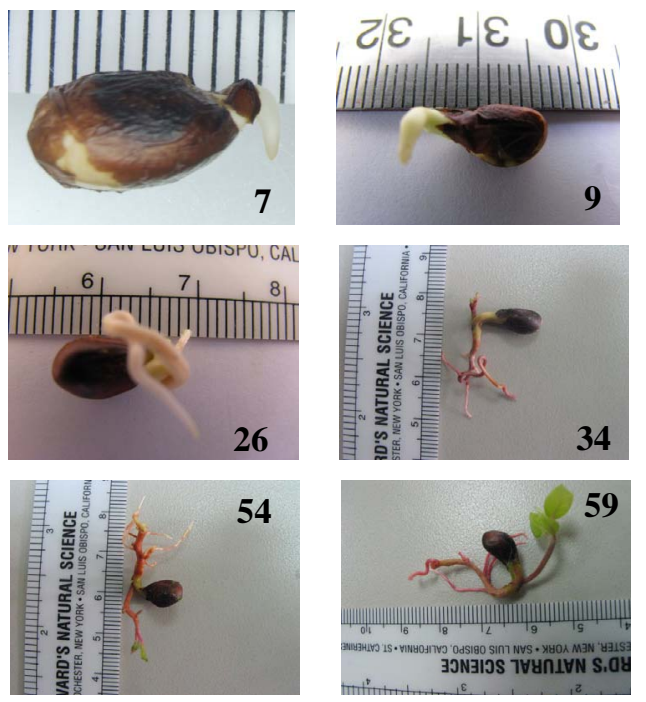

Figure 3. Acridocarpus orientalis germination and radical emergence stages. Days since start of germination are shown. 
the emergence and the growth rate of these roots is very fast. The aerial part showed also a rapid growth rate. The first leaf emerged 1 to 3 weeks after root emergence. The plants continued to develop its root system even after leaf emergence.

The biggest problem encountered during this germination trial is the mortality of germinated and non-germinated seeds. Many seeds died before their germination, but a considerable number died at the stage of 2, 3 and even 6 leaves.

Even if the laboratory essay showed a higher rate of seed germination, no seedlings could survive to the end of the experiment. However, six plants issued from the directly sowed seeds in pots in the greenhouse are still surviving. It may be a problem of acclimation to the greenhouse environment.

\section{Discussion}

The results of this study showed that $A$. orientalis seeds were not dormant. In fact, $32 \%$ of seeds germinated and all the non-germinated seeds were viable. The higher percent germination was observed with seeds soaked in water. This can be explained by the removal of the viscous layer coating all seeds of $A$. orientalis, after being soaked in water. This result confirmed that of reports [18] indicating that all the priming treatments improved the emergence, seedling growth and reserve metabolism.

The rate of germinated seed mortality, underline the need for further future investigations into post germination conditions and acclimation.

Observations of root growth revealed the ability of this species to survive in dry regions. It developed long principal roots with many secondary roots, which highlight the ability of $A$. orientalis to extract soil moisture even in deep substrate levels. The potential water uptake in any soil layer depends on the soil water content and the root density, and for whole soil profiles water uptake depends on the rooting depth and total root length [19].

\section{Conclusion}

This study provided some much needed information about the germination conditions and the growth stages of the rare plants species A. orientalis. However, the lack of information on its growth requirements is urgently needed to be addressed, in order to overcome A. orientalis rare status in the UAE. Additionally, improved understanding of the species soil and habitat preferences, through soil nutrient analysis within its niche in Jabal Hafeet are also required. Ecological interactions of the species could offer more information about the growth conditions of A. orientalis, which will certainly improve the rate of success to protect it.

\section{Acknowledgements}

The funding by the Mohamed bin Zayed Species Conservation Fund is much appreciated (Fund No. 21S031). The investigators would also like to express their sincere appreciation to the Office of Research Support and Sponsored Projects at the United Arab Emirates University for their support and the management of this project. The support from the Biology Department and the Faculty of Science is also much appreciated. Assistance from all students in any parts of this project is appreciated.

\section{REFERENCES}

[1] P. A. Parsons, "Environmental Stresses and Conservation of Natural Populations,” Annual Review of Ecology and Systematics, Vol. 20, No. 1, 1989, pp. 29-49. doi:10.1146/annurev.es.20.110189.000333

[2] A. El-Keblawy and T. Ksiksi, "Artificial Forests as Conservation Sites for the Native Flora of the UAE," Forest Ecology and Management, Vol. 213, No. 1-3, 2005, pp. 288-296. doi:10.1016/j.foreco.2005.03.058

[3] G. Brown and S. Sakkir, "The Vascular Plants of Abu Dhabi Emirate,” Environmental Research \& Wildlife Development Agency, August 2004.

[4] R. Choukr-Allah and M. C. Harrouni, "The Potential Use of Halophytes under Saline Irrigation in Morocco (Abstract)," Symposium on the Conservation of Mangal Ecosystems, Al Ain, 1996, pp. 15-17.

[5] G. Brown and B. Böer, "Terrestrial Habitats,” In: P. Hellyer and S. Aspinall, Eds., The Emirates-A Natural History, Trident, London, 2005, pp. 93-108.

[6] A. El-Keblawy, T. Ksiksi and H. Elalgamy, "Camel Grazing Affects Species Diversity and Community Structure in the Arid Deserts of the United Arab Emirates,” Journal of Arid Environment, Vol. 73, No. 3, 2009, pp. 347-354. doi:10.1016/j.jaridenv.2008.10.004

[7] G. Brown, J. Peacock, R. Loughland and G. A. Aldrami, "Coastal and Terrestrial Ecosystem Management Requirements in the GCC States,” ERWDA Internal Report, UAE, 2003.

[8] S. A. Chaudhary and A. A. Al-Jowaid, "Vegetation of the Kingdom of Saudi Arabia,” Ministry of Agriculture \& Water, Riyadh, 1999, 689 p.

[9] H. N. Le Houérou, "The Desert and Arid Zones of Northern Africa,” In: M. Evenari, D. W. Goodall and I. NoyMeir, Eds., Hot Deserts and arid Shrublands, Ecosystems of the World, Vol. 11B, Elsevier, Amsterdam, 1986, pp. 101-147.

[10] G. Brown, "Factors Maintaining Plant Diversity in Degraded Areas of Northern Kuwait," Journal of Arid Environments, Vol. 54, No. 1, 2003, pp. 183-194. doi:10.1006/jare.2001.0880

[11] U. Deil, "Halophytic Vegetation along the Arabian Coast -A Zonal or Linked to Climatic Zones?” Phytocoenologia, Vol. 30, 2000, pp. 591-611.

[12] G. Brown and S. Sakkir, "Flora and Vegetation in Jebal 
Hafit,” In: S. Aspinall and P. Hellyer, Eds., Jebal HafitA Natural History, Emirates Natural History Group, Abu Dhabi, 2004, pp. 65-93.

[13] T. N. Kaye, "Propagation of Endangered Species: Variable Germination of Pink Sand verbena from Pacific Coast Beaches," Combined Proceedings of the International Plant Propagators Society, Vol. 49, 1999, pp. 617621.

[14] D. A. Falk, C. I. Millar and M. Olwell, "Restoring Diversity, Strategies for Reintroduction of Endangered Plants," Island Press, Washington DC, 1996.

[15] E. Andrieu, M. Debussche, J. Thompson, W. Heintz, V. Vaudey, P. Gauthier and V. Deconchat, "Trajectoires sylvicoles et Conservation des Espèces Végétales: De l'Analyse Historique à l'Expérimentation," 3èmes Journées Francophones des Sciences de la Conservation de la Biodiversité sous l'Egide de l'IFR 119 “MontpellierEnvironnement-Biodiversité”, Marsh 2009.
[16] J. Lorite, M. Ruiz-Girala and G. Castro, "Patterns of Seed Germination in Mediterranean Mountains: Study on 37 Endemic or Rare Species from Sierra Nevada, SE Spain," Candollea, Vol. 62, No. 1, 2007, pp. 1-12.

[17] J. D. Bewley and M. Black, "Physiology and Biochemistry of Seeds in Relation to Germination. Vol. 1. Development, Germination and Growth,” Springer-Verlag, New York, 1978.

[18] M. Farooq, A. Wahid, N. Ahmad and S. A. Asad, "Comparative Efficacy of Surface Drying and Re-Drying Seed Priming in Rice: Changes in Emergence, Seedling Growth and Associated Metabolic Events," Paddy Water of Environment, Vol. 8, No. 1, 2010, pp. 15-22. doi:10.1007/s10333-009-0170-1

[19] B. Klepper and R. W. Rickman, "Modeling Crop Root Growth and Function," Advances in Agronomy, Vol. 4, 1990, pp. 113-132. doi:10.1016/S0065-2113(08)60820-2 